\title{
Understanding the Effect of Unintentional Doping on Transport Optimization and Analysis in Efficient Organic Bulk-Heterojunction Solar Cells
}

\author{
Florent Deledalle, ${ }^{1}$ Thomas Kirchartz, ${ }^{2,3, *}$ Michelle S. Vezie, ${ }^{4}$ Mariano Campoy-Quiles, ${ }^{5}$ \\ Pabitra Shakya Tuladhar, ${ }^{1}$ Jenny Nelson, ${ }^{4}$ and James R. Durrant ${ }^{1, \dagger}$ \\ ${ }^{1}$ Department of Chemistry and Centre for Plastic Electronics, Imperial College London, \\ South Kensington Campus, SW7 2AZ London, United Kingdom \\ ${ }^{2}$ IEK5-Photovoltaics, Forschungszentrum Jülich, 52425 Jülich, Germany \\ ${ }^{3}$ Faculty of Engineering and CENIDE, University of Duisburg-Essen, \\ Carl-Benz-Strasse 199, 47057 Duisburg, Germany \\ ${ }^{4}$ Department of Physics and Centre for Plastic Electronics, Imperial College London, \\ South Kensington Campus, SW7 2AZ London, United Kingdom \\ ${ }^{5}$ Institut de Cincia de Materials de Barcelona (ICMAB-CSIC), Esfera de la UAB, 08193 Bellaterra, Spain
} (Received 8 October 2014; published 24 March 2015)

\begin{abstract}
In this paper, we provide experimental evidence of the effects of unintentional $p$-type doping on the performance and the apparent recombination dynamics of bulk-heterojunction solar cells. By supporting these experimental observations with drift-diffusion simulations on two batches of the same efficient polymer-fullerene solar cells with substantially different doping levels and at different thicknesses, we investigate the way the presence of doping affects the interpretation of optoelectronic measurements of recombination and charge transport in organic solar cells. We also present experimental evidence on how unintentional doping can lead to excessively high apparent reaction orders. Our work suggests first that the knowledge of the level of dopants is essential in the studies of recombination dynamics and carrier transport and that unintentional doping levels need to be reduced below approximately $7 \times 10^{15} \mathrm{~cm}^{-3}$ for full optimization around the second interference maximum of highly efficient polymer-fullerene solar cells.
\end{abstract}

DOI: 10.1103/PhysRevX.5.011032

\section{INTRODUCTION}

Solution-processed organic solar cells, such as those based upon polymer-fullerene blends, represent one potential technological route to help taking up the challenges presented by climate change and energy equity. There is currently extensive research on the design and synthesis of low-band-gap semiconducting polymers to enhance the efficiency of such solar cells [1], and many families of polymers and synthesis routes are currently being explored [2-8]. In this paper, we focus upon one polymer design parameter that has received relatively little attention in such research to date-namely, the impact of chemical doping. Doping is widely employed as one of the key design parameters in inorganic semiconductors to control the device electrostatics and carrier densities such that a

\footnotetext{
*Corresponding author.

t.kirchartz@fz-juelich.de

Corresponding author.

j.durrant@imperial.ac.uk

Published by the American Physical Society under the terms of the Creative Commons Attribution 3.0 License. Further distribution of this work must maintain attribution to the author(s) and the published article's title, journal citation, and DOI.
}

Subject Areas: Chemical Physics,

Semiconductor Physics desired functionality is achieved; it is, for example, used to generate directionally the electric field that separates photogenerated charges in $p$ - $n$ homojunction diodes used for inorganic photovoltaic devices $[9,10]$. In contrast, in solution-processed organic solar cells, a built-in electric field is typically generated by appropriate contact materials like a low work-function metal and a transparent and conductive oxide or organic hole conductor. The electrode selectivity may be enhanced using interlayers. These electric fields drive photogenerated charges to the required device electrodes, with the initial charge separation being primarily a process at a molecular level driven by a difference in the electronic energy levels of the donor and acceptor components of the photoactive layer. Molecular doping has been employed in such devices to enhance the performance of electron- and hole-collection layers and is generally perceived as beneficial in these layers [11-14]. However, doping in the photoactive layer of organic solar cells has received relatively little attention to date. Such doping is nearly always unintentional [15-22] but has been shown to have a potentially large influence on the distribution of electric fields in the device [23,24]. Understanding how device performance and, in particular, charge-carrier transport and recombination dynamics 
respond to changes in electric field distribution resulting from inadvertent photoactive-layer doping is therefore a key consideration, both with regard to the synthetic and purification strategies employed to control such doping levels and its impact on the choice of device architecture for optimum solar-cell performance.

In this paper, we present experimental data on organic solar cells fabricated using two batches of nominally the same donor polymer (poly[[2,5-bis(2-octyldodecyl)-2,3,5,6-tetrahydro3,6-dioxopyrrolo[3,4-c]pyrrole-1,4-diyl]-alt-[[2,2'-(2,5thiophene)bis-thieno[3,2-b]thiophen]-5,5'-diyl]]) (DPP-TT-T) that show substantially different levels of doping as measured by capacitance measurements. DPP-TT-T is a low-band-gap DPP polymer that has been synthesized by microwave Stille coupling; the synthesis route is described by Ref. [25]. When blended with 6,6-phenyl $\mathrm{C}_{71}$-butyric acid methyl ester $\left(\mathrm{PC}_{71} \mathrm{BM}\right)$, DPP-TT-T-based devices show promising device performances [26]. The differences in average molecular weight in number, in weight, and polydispersity can be found in Sec. V, along with details of materials and device fabrication. Polymer purification has previously been empirically shown to have a significant impact on the device performance [27-32]. We use currentvoltage curves, light-intensity-dependent photocurrent, and charge-extraction (CE) measurements to study the influence of doping on device performance, the thickness dependence of device behavior, and the interpretation of transient photocurrent (TPC) and photovoltage (TPV) measurements. To interpret the experimental observations, we use numerical drift-diffusion simulations that incorporate the effect of doping on the electrostatics of the device.

\section{THEORETICAL BACKGROUND, DEPLETION ZONE, AND CHARGE COLLECTION IN ORGANIC SOLAR CELLS}

In most models of organic solar cells [33-43], the photoactive-layer acceptor-donor blend sandwiched between two electrodes is considered as an intrinsic semiconductor, with the band profile linearly varying at equilibrium. Such models include the assumption that the depth of the depletion layer formed by contacting the photoactive layer with the electrodes of the device is much greater than the photoactive-layer thickness, resulting in a position-independent electric field within the device. To illustrate the influence of doping on the electric field distribution in such solar cells, we calculate band diagrams (at $0-\mathrm{V}$ applied bias in the dark) for devices with low and high doping, as shown in Fig. 1, representative of the doping levels measured experimentally below for devices fabricated with the two batches of DPP-TT-T. These band diagrams are calculated using device simulations with advanced semiconductor analysis (ASA). A detailed description of the simulations is provided in Refs. [44,45] and in the Supplemental Material [46,47]. Figure 1(a) shows the case of a low, $p$-type doping density

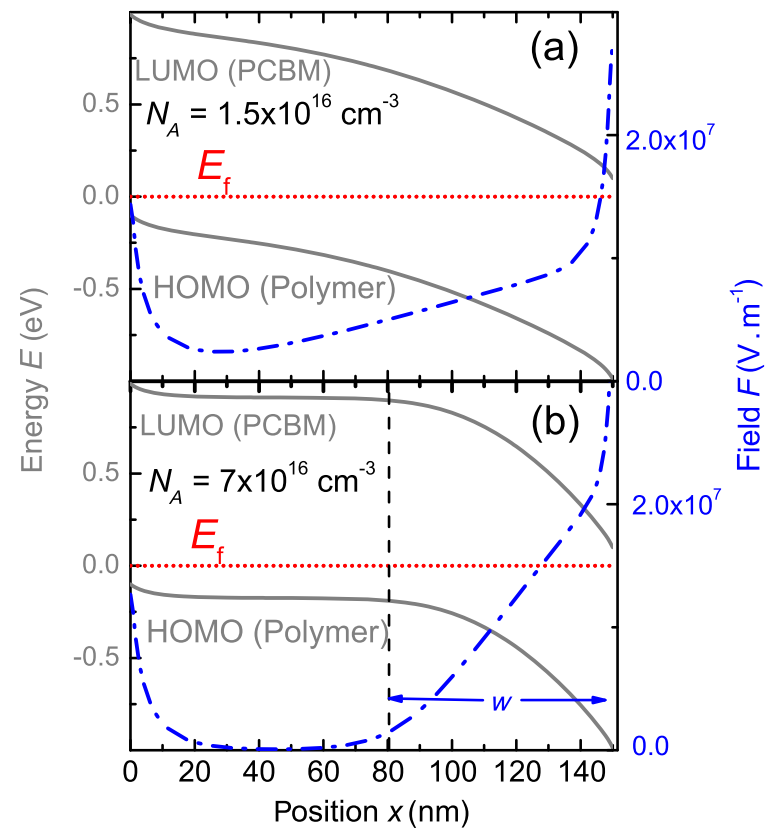

FIG. 1. Simulated band diagram obtained with advanced semiconductor analysis in the dark at short circuit for $150-\mathrm{nm}$ thick active-layer devices at two $p$-type doping levels: (a) $1.5 \times 10^{16} \mathrm{~cm}^{-3}$ and (b) $7 \times 10^{16} \mathrm{~cm}^{-3}$. The devices are illuminated from the glass and ITO at position 0. Although the undoped device is still fully depleted at $150 \mathrm{~nm}$, in the doped version, the strong electric field (dash-dotted lines) will develop only over a part of the total active-layer thickness.

$\left(1.5 \times 10^{16} \mathrm{~cm}^{-3}\right)$, leading to a relatively homogeneous electric field as a function of position in this example of an active-layer thickness of $150 \mathrm{~nm}$. In the case of a higher ( $p$-type) doping concentration $\left(7 \times 10^{16} \mathrm{~cm}^{-3}\right)$, Fig. 1(b) shows that the electric field is distributed such that it is high close to the cathode and much lower further away from that electrode. This inhomogeneity of the electric field within the active layer occurs because the width of the space-charge region

$$
w=\sqrt{\frac{2 \varepsilon_{0} \varepsilon_{r}\left(V_{\mathrm{BI}}-V\right)}{q N_{A}}}
$$

is much lower than the active-layer thickness. Here, $\epsilon_{r} \epsilon_{0}$ is the total permittivity of the active material, $q$ the elementary charge, $V_{\mathrm{BI}}$ the built-in potential and $V$ the applied voltage across the two electrodes, and $N_{A}$ the doping density. In the doped device, charge-carrier collection can be expected to be efficient at short circuit within the approximately 60 -nm-thick space-charge layer near the cathode. However, for the $90 \mathrm{~nm}$ closest to the anode, the electric field is relatively low, and the film is not depleted, such that the minority carriers (electrons) have to diffuse to the edge of the space-charge region (SCR) at $x=90 \mathrm{~nm}$ while in the presence of a large concentration of holes, which can be expected to result in 
a poor collection efficiency. In contrast, if the doping is low enough that the width of the space-charge region is comparable to the active-layer thickness, as shown in Fig. 1(a), the active layer will be fully depleted, allowing efficient charge collection. These simulations of band diagrams show that the active layer can be partially depleted at short circuit even at thicknesses commonly used for standard device fabrication at accessible doping levels (e.g., $d=150 \mathrm{~nm}$ and $N_{A}=7 \times 10^{16} \mathrm{~cm}^{-3}$ ). The results are consistent with previous modeling work $[23,24]$ and with our recent comparison of the photocurrent-generation efficiency between inverted and conventional configuration devices employing a doped photoactive layer [48]. The rest of the paper addresses the impact of inherent doping levels on the optimization of carrier transport and the interpretation of measurements of nongeminate recombination in devices.

\section{RESULTS AND DISCUSSION}

Here, we show that even without the deliberate addition of molecular dopants, the level of doping in typical polymer batches can vary by over an order of magnitude and can have a large impact on fundamental optoelectronic properties of the device.

\section{A. Mott-Schottky analysis of material doping}

Mott-Schottky analysis using impedance measurements is used to access the apparent doping levels of DPP-TT-T $\mathrm{PC}_{71} \mathrm{BM}$ solar cells fabricated using the two different batches of DPP-TT-T employed in this study, following procedures detailed previously [49-54]. The capacitance is varied by the change in space-charge layer $w$ controlled by the dc applied bias following the relation $C=\varepsilon_{0} \varepsilon_{r} A / w$. Nevertheless, the space-charge layer $w$ is linked to the apparent doping level $N_{A}$ by the definition of the spacecharge region as stated above in Eq. (1). Consequently, the level of doping at the distance $x=\epsilon_{r} \epsilon_{0} A / C$ from the junction (which in the case of conventional $p$-type doping is on the cathode side) can be deduced from the gradient of the $C^{-2}$ function of applied bias $V$ according to

$$
C^{-2}=\frac{2\left(V_{\mathrm{BI}}-V\right)}{q \varepsilon_{0} \varepsilon_{r} A^{2} N_{A}} .
$$

Figure 2(a) shows the results of such analyses, using capacitance-voltage measurements at $1 \mathrm{kHz}$ over the range $[-3 ;+1] \mathrm{V}$. The data presented here correspond to a 160 -nm-thick device for the undoped case and a 390-nm device for the doped case. These data yield apparent doping levels of approximately $1.5 \times 10^{16} \mathrm{~cm}^{-3}$ (solid triangles) for the first batch (labeled in what follows undoped DPP-TT-T ${ }^{u}$ ) to approximately $7-9 \times 10^{16} \mathrm{~cm}^{-3}$ (open squares) for the second batch (labeled doped DPP-TT-T ${ }^{d}$ ). These measurements are conducted multiple times on each device; the apparent doping values stay constant to within
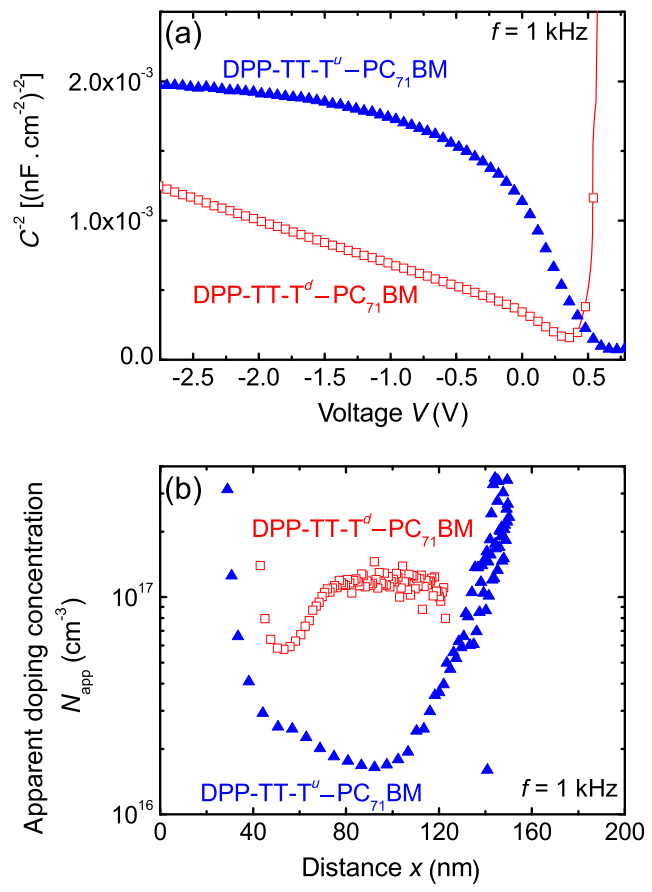

FIG. 2. (a) Mott-Schottky plot in the dark at $1 \mathrm{kHz}$ for two thick devices of undoped DPP-TT-T ${ }^{u}-\mathrm{PC}_{71} \mathrm{BM}$ (solid triangles) and doped DPP-TT-T ${ }^{d}-\mathrm{P}_{71} \mathrm{BM}$ (open squares). The capacitance is inversely proportional to the space-charge-layer thickness that is controlled by the applied bias. Nevertheless, the space-charge layer is also governed by the doping level. (b) The gradient of the $C^{-2}$ function of $V$ is inversely proportional to the apparent doping level $N_{A}$. There are strong variations of the level of unintentional doping in our system.

$\pm 13 \%$ over a month for the same device. Previous work on $p$-conjugated polymers reported apparent doping levels ranging from $10^{14}$ to $10^{17} \mathrm{~cm}^{-3} \quad[15,17,21,24,55,56]$. Mott-Schottky analysis cannot determine the type of doping. Nevertheless, as will be developed below, the behavior of the doped devices leads us to conclude that in our case, the doping is $p$ type. Here, assuming a homogenous distribution of dopants $N_{A}$, these doping sites would on average be spaced by $N_{A}^{(-1 / 3)} \approx 25 \mathrm{~nm}$ in the doped batch. These two systems DPP-TT-T ${ }^{u}$ and DPP-TT-T ${ }^{d}$ are ideal for the experimental study of the effects of doping and will be the reference systems for the rest of the paper referred to hereafter as "undoped" and "doped" devices.

\section{B. Device current-voltage performance as a function of DPP-TT-T - PC $\mathrm{P}_{71} \mathrm{BM}$ layer thickness}

As detailed in the theory section above, doping is expected to impact particularly on the space-charge-layer width $w$ of the device and therefore upon device performance as a function of photoactive-layer thickness. To study the influence of doping experimentally, devices are fabricated as a function of photoactive-layer thickness with a conventional 
architecture indium tin oxide (ITO)/PEDOT PSS/DPP-TT-T $-\mathrm{PC}_{71} \mathrm{BM}(1: 2 w / w) / \mathrm{Ca} / \mathrm{Al}$ using the two different batches. The protocol to make the devices follows that in Ref. [25], and more details are presented in Sec. V. Figures 3(a) and 3(b) present the current-voltage responses under air mass (AM)1.5-G illumination (solid lines) and in the dark (dashed lines) for both thickness series using DPP-TT-T ${ }^{u}-\mathrm{PC}_{71} \mathrm{BM}\left(N_{A} \approx 1.5 \times 10^{16} \mathrm{~cm}^{-3}\right)$ and DPP-TT-T ${ }^{d}-\mathrm{PC}_{71} \mathrm{BM}\left(N_{A} \approx 8 \times 10^{16} \mathrm{~cm}^{-3}\right)$. The performances of the presented devices are summarized in Table SI in the Supplemental Material [46]. Although the thin devices of both the doped and undoped series generally show a good performance, in particular, with high fill factors (58\% and $62 \%$ for the doped and undoped devices, respectively) indicative of efficient charge-carrier collection,
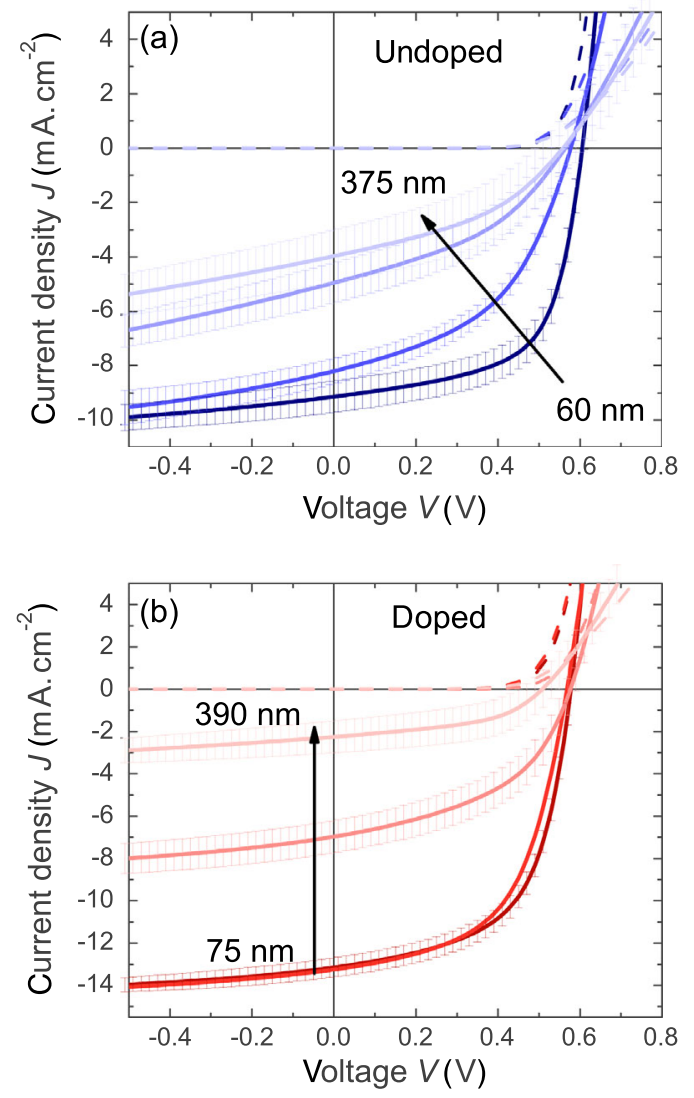

FIG. 3. Experimental AM1.5 (solid lines) and dark (dashed lines) $J-V$ curves at increasing thicknesses for the two batches with different doping levels (a) DPP-TT-T ${ }^{u}-\mathrm{PC}_{71} \mathrm{BM}$ $\left(N_{A} \approx 1.5 \times 10^{16} \mathrm{~cm}^{-3}\right)$ at 60-, 160-, 350-, and 375-nm thickness and (b) DPP-TT-T ${ }^{d}-\mathrm{PC}_{71} \mathrm{BM}\left(N_{A} \approx 8 \times 10^{16} \mathrm{~cm}^{-3}\right)$ at $75-$, $81-$, 160-, and 390-nm thickness. The $y$-axis error bars correspond to the standard deviations measured on at least four pixels. The concept of the insufficient mobility-lifetime product behind the typical degradation of the carrier transport with thickness as observed in (a) cannot explain the behavior of the doped counterparts shown in (b) that have higher fill factor at comparative thicknesses. the trends observed with increasing thickness are significantly different.

Figure 3(a) shows a strongly voltage-dependent current density under illumination and therefore a voltage-dependent charge-carrier collection in the devices with low doping concentration. This voltage dependence of the efficiency of charge collection becomes stronger with increasing thickness. This typical drop of $F F$ and to a lesser degree $J_{\mathrm{SC}}$ with increasing device thickness has already been reported in different systems like in Refs. [57-59] and addressed in Refs. [24,38,60-67]. Here, the impact of nongeminate recombination on the fill factor is further supported by the successful predictions of open-circuit voltages and current-density-voltage responses at different light levels on thin fully depleted devices by applying the methodology explained elsewhere based on transient photovoltage and charge-extraction analyses $[43,68]$. The results can be found in the Supplemental Material, Figs. S1 and S2 [46], and assume, in particular, a negligible loss in the fourth quadrant due to field-dependent generation for this blend ratio $[43,68,69]$.

We now consider the extent to which these experimental data are consistent with the simple device model presented in Sec. II. Charge collection for the undoped thickness series can be understood using the band diagram presented in Fig. 1(a). Because of a low doping level, the simulated band diagram is fully depleted and the electric field is relatively uniform and strong at short circuit. Toward forward bias, the electric field would decrease, resulting in strong voltage-dependent charge-collection losses. With increasing thickness, the electric field is reduced, collection competes less effectively with recombination, and the fill factor is decreased substantially. The $J_{\mathrm{SC}}$ is also reduced, although to a lesser degree, as the electric field at short circuit is for all thicknesses larger than the electric field at the maximum power point. The behavior shown in Fig. 3(a) is characteristic of an insufficiently high-mobility-lifetime product. In the case of fully depleted solar cells, the ratio of the so-called drift length $L_{\text {drift }} \approx \nu \times \tau \approx \mu E \times \tau \approx$ $\mu\left(V_{\mathrm{BI}} / d\right) \times \tau$ to the thickness controls the chargecollection efficiency. At a given built-in voltage $V_{\mathrm{BI}}$, the ratio $L_{\text {drift }} / d$ decreases with $d^{2}$, thereby leading to the strong thickness dependence of the fill factor observed. Overall, the performance degradation will eventually be the result of the combined consequences of interference effects within the active layer and the competition between carrier collection and recombination dynamics.

In contrast, in the case of doped devices presented in Fig. 3(b), the fill factor stays high while the short-circuit current decreases significantly. Consequently, although the power-conversion efficiencies of the two series are decreasing with thickness, the decrease of the overall performance of the doped series is more substantial due to this large drop in $J_{\mathrm{SC}}$. In the doped case, the behavior in thickness shown in Fig. 3(b) can be rationalized using the band diagram 
presented in Fig. 1(b). For doping levels on the order of $N_{A} \approx 7 \times 10^{16} \mathrm{~cm}^{-3}$, we estimate the width of the spacecharge region to be approximately $70-80 \mathrm{~nm}$ by applying the definition given by Eq. (1). In this second case, the field-assisted collection only happens partially through the active layer, as pictured in Fig. 1(b). Here, the common way of understanding charge collection explained earlier based on the drift length throughout the entire active layer is not correct since the drift current of the minority carrier is negligible in the neutral region. Most charge carriers that contribute to the photocurrent are generated in the small space-charge region, whose width is fixed by the doping level and does not change with active-layer thickness. Thus, the short-circuit current density will be reduced with thickness as less light is absorbed in the space-charge region, but the $F F$ will stay rather constant as the width of the space-charge region does not change and the diffusion of carriers generated out of the space-charge region is not voltage dependent. Although the concentration of holes as majority carriers will not be affected by recombination, the neutral zone has a finite conductivity controlled by hole concentration and hole mobility that will affect the internal series resistance of the device, and thus a slight decrease of fill factor with thickness can be observed in this series. We note that even with a density of dopants on the order of $N_{A} \approx 1.5 \times 10^{16} \mathrm{~cm}^{-3}$, the width of the space-charge region becomes smaller than the device thickness, resulting in additional $J_{\mathrm{SC}}$ losses beyond $150 \mathrm{~nm}$. Nevertheless, the fill factor of these low-doping-level devices has already substantially degraded before the active-layer thickness starts to be partially depleted.

It can be concluded that the different thickness dependencies of the experimental $J-V$ data for our doped and undoped devices are consistent with our device model. We now go on to consider the impact of doping on device performance in more detail.

\section{Thickness dependence of the short-circuit current}

The measured increase in absorbance with thickness is shown in Fig. 4(a) for thin films of the doped blend. This increase in light absorption with thickness is in clear contrast with the decrease in $J_{\mathrm{SC}}$ over the thickness range (see Fig. 3) and indicative of increased collection losses with device thickness. A more quantitative analysis of light absorption in the devices requires consideration of optical interference effects. Shifts in interference pattern as a function of active-layer thickness affect the amount of light generated in the space-charge region (where charge collection is more efficient). As such, optical modeling is employed to calculate the charge-generation rate $G_{x}$ as a function of active-layer thickness. Figure 4(b) shows the integrated generation rate $G$ within the space-charge zone at different thicknesses based on a simple matrix-transfer algorithm using $n k$ data measured with ellipsometry on an equivalent blend film and shown in the Supplemental
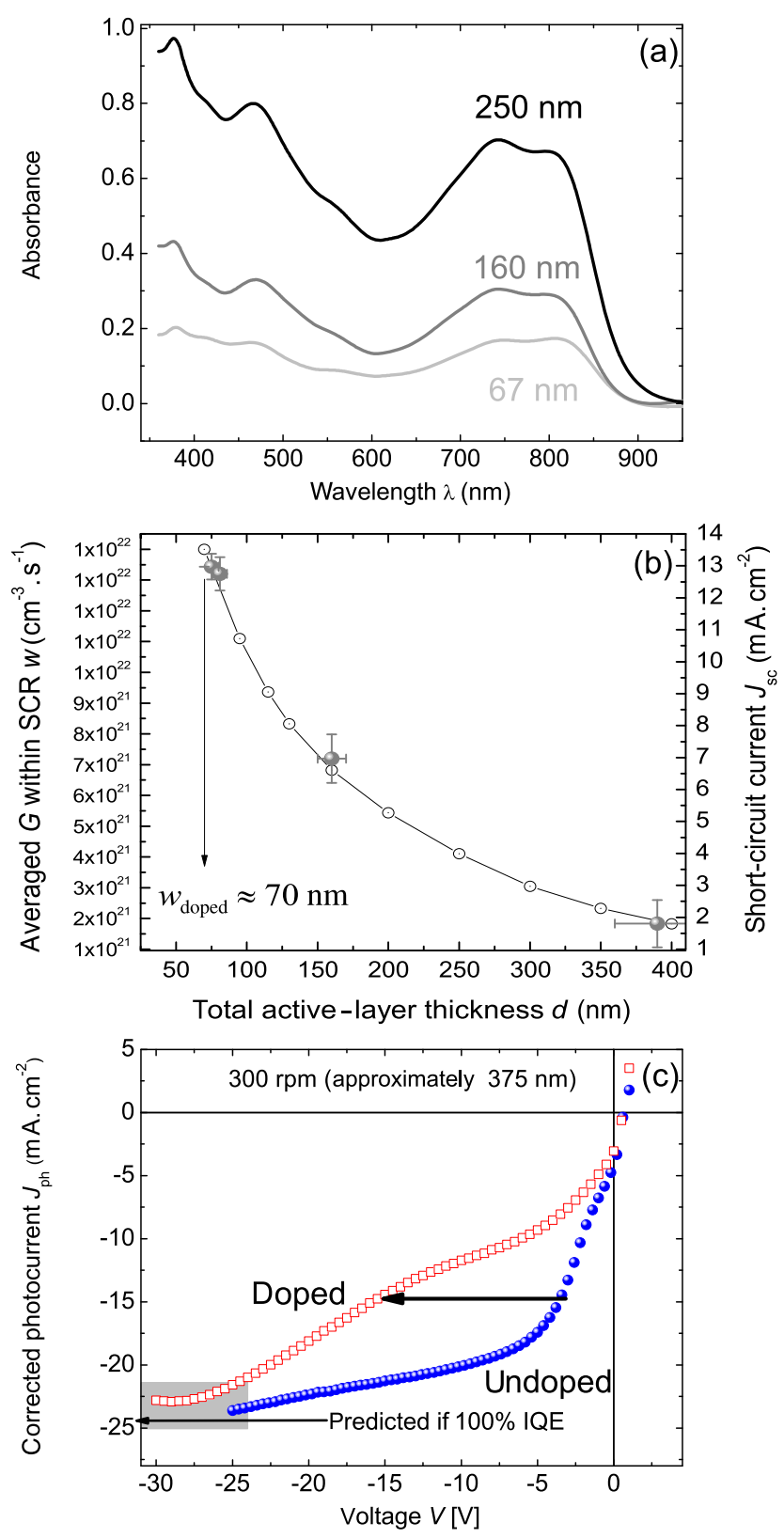

FIG. 4. (a) UV-vis spectra showing the absorbance between 350 and $950 \mathrm{~nm}$ of a thickness series of DPP-TT-T - $\mathrm{PC}_{71} \mathrm{BM}$ devices in conventional architecture with a high doping level ( $N_{A} \approx 1 \times 10^{17} \mathrm{~cm}^{-3}$, from a previous batch). (b) Averaged generation rate $G_{x}$ calculated by the matrix-modeling technique within the space-charge region $w_{\text {doped }}$ (open circles) at different activelayer total thicknesses for the doped $\left(N_{A} \approx 7-8 \times 10^{16} \mathrm{~cm}^{-3}\right)$ batch. The measured short-circuit current $J_{\mathrm{SC}}$ (solid circles) for doped devices at the same thickness is shown. The $Y$ error bar corresponds to the standard deviation measured on at least four pixels and $x$ error bars to the uncertainty on the measurements of the thickness of the active layer. (c) Corrected photocurrent $J_{\mathrm{ph}}=$ $J_{\text {light }}-J_{\text {dark }}$ for two DPP-TT-T $-\mathrm{PC}_{71} \mathrm{BM}$ devices of approximately the same thickness (approximately $375 \mathrm{~nm}$ ) at two different doping levels (open square $N_{A}=7 \times 10^{16} \mathrm{~cm}^{-3}$ and solid sphere $\left.N_{A}=1 \times 10^{16} \mathrm{~cm}^{-3}\right)$. 
Material, Figs. S3-S5 [46]. These calculations yield a continuous decrease of $J_{\mathrm{SC}}$ with active-layer thickness in the case of high $p$-type doping level (open circles) and are in quantitative agreement with our experimentally observed decrease in short-circuit current densities with thickness for the series of doped devices (filled circles). To further support the hypothesis that the loss of the extra carriers photogenerated in greater active-layer thicknesses in doped and undoped batches has different fundamental origins, the corrected photocurrent $J_{\mathrm{ph}}(V)=J_{\text {light }}(V)-J_{\text {dark }}(V)$ is measured to explore the responses of doped and undoped devices from forward to reverse bias. The device thicknesses are both measured to be approximately $375 \mathrm{~nm}$ (spin speed $300 \mathrm{rpm}$ ). Figure 4(c) shows the obtained corrected photocurrents for the doped (open squares) and the undoped (solid spheres) devices. The obtained values in far reverse bias $[-30 ;-25] \mathrm{V}$ are substantially superior to their short-circuit currents even in the case of the doped device and very similar between the two doping levels. The values of corrected photocurrents obtained at far reverse bias converge toward the $J_{\mathrm{SC}}$ values predicted assuming perfect collection ["perfect collection" synonymous of $100 \%$ internal quantum efficiency (IQE)], calculated using the matrix-modeling technique (see the Supplemental Material, Fig. S3 [46]). According to Eq. (1), the width of the space-charge region increases with negative bias and the increase in electric field leads to longer drift lengths $L_{\text {drift }}$ at a given $\mu \tau$ product and therefore better collection. In the case of the undoped device, which is much more depleted than the doped one at $0 \mathrm{~V}$, the sweep in reverse bias will continuously increase the collection efficiency with increasing negative bias. In the case of the doped device, this increase will be much slower, as initially only the width of the space-charge region will increase while most of the device is still field neutral. Only once the doped device is fully depleted will it approach the same level of photocurrent as the undoped device.

This observation is crucial for device optimization, as it shows that although a promising organic photovoltaic material might show very good transport properties, trying to optimize the device toward the second interference maximum to obtain higher short-circuit current is doomed to failure if the material happens to be unintentionally doped. This observation confirms that unintentional doping will be overall detrimental even if thin devices show relatively well-balanced transport, as explained in Ref. [23]. However, the modeling study in the previous reference also shows that doping can be beneficial for thin devices if the carrier mobilities were initially asymmetric. Here, we measure the effective drift mobility of thin (fully depleted) undoped DPP-TT-T ${ }^{u}-\mathrm{PC}_{71} \mathrm{BM}$ and doped DPP-TT- $\mathrm{T}^{d}-\mathrm{PC}_{71} \mathrm{BM}$ devices using charge extraction at short circuit following the method previously used in Ref. [70]. The effective drift mobilities obtained are represented in the Supplemental Material, Fig. S6
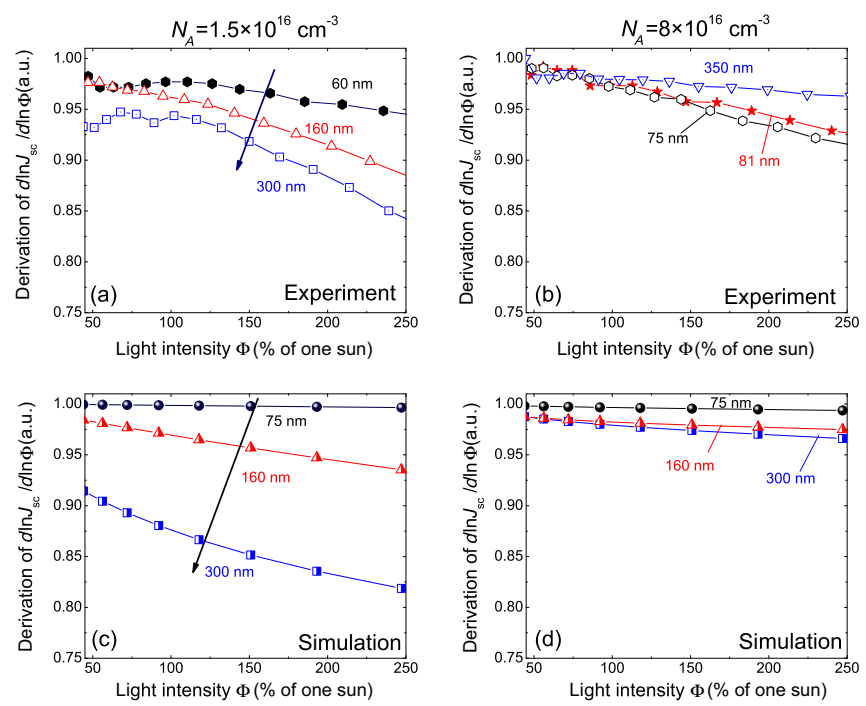

FIG. 5. Linearity of the short-circuit current $J_{\mathrm{SC}}$ with illumination at different thicknesses for DPP-TT-T $-\mathrm{PC}_{71} \mathrm{BM}$ devices with a low level of doping [(a) experimental and (c) simulation] and a high level of doping [(b) experimental and (d) simulation]. The loss of linearity is compatible with the second-order loss process. However, the linearity does not appear to be degraded in the doped thickness series while there is substantial nongeminate recombination within the neutral region.

$[46,70]$. Both effective drift mobilities are at $1.2 \times 10^{-4} \pm$ $3 \times 10^{-5} \mathrm{~cm}^{2} \mathrm{~V}^{-1} \mathrm{~s}^{-1}$. This measurement suggests that the observed differences in current-voltage curves are not due to differences in mobilities between the two batches.

Furthermore, one assay of the relevance of nongeminate recombination at short circuit is the analysis of the linearity of $J_{\mathrm{SC}}$ as a function of illumination level $\Phi$. Indeed, it has been well established that the short-circuit current in polymer-fullerene solar cells tends to show a power law of type $J_{\mathrm{SC}} \propto \Phi^{\alpha}$ with $\alpha \leq 1$; the sublinearity of $J_{\mathrm{SC}}$ with illumination has been interpreted as a consequence of the development of higher-order carrier-loss processes at short circuit [60,62,71-75]. Figures 5(a)-5(d) present $d \ln \left(J_{\mathrm{SC}}\right) / d \ln (\Phi)$ at different illumination levels as obtained experimentally and from simulation corresponding to a low doping level. The list of parameters used for these simulations can be found in the Supplemental Material, Table SII [46]. In the undoped case, the linearity of the short-circuit current is a correct assay of the degradation of carrier transport under short-circuit conditions. The higher linearity of $J_{\mathrm{SC}}$ for the thin undoped device compared with a thicker undoped device is indeed an indication of less bimolecular recombination at short circuit. This degradation of the linearity of $J_{\mathrm{SC}}$ with light can be observed in other undoped systems like a PCDTBT: $\mathrm{PC}_{71} \mathrm{BM}$ thickness series shown in the Supplemental Material, Fig. S7 [46]. However, we find experimentally that the trend is not followed in the thickness series of the doped devices, as presented in Fig. 5(b). In this case, the 
linearity of $J_{\mathrm{SC}}$ stays high even for devices as thick as $350 \mathrm{~nm}$, where the space-charge layer is thinner than the thickness of the absorber layer. Here, the substantial number of minority carriers generated outside of the space-charge region, which recombine with the excess of holes, is not translated into the degradation of the linearity of $J_{\mathrm{SC}}$, which is composed mostly of the carriers generated within the space-charge region whose thickness is fixed by the high doping level. The absence of degradation of the linearity of $J_{\mathrm{SC}}$ with light is because the recombination of minority carriers within the neutral region occurs with a large excess of holes, therefore is pseudo-first-order, and consequently would not affect how $J_{\mathrm{SC}}$ scales with illumination. This change in behavior is captured in the simulation when the doping level is increased from $1.5 \times 10^{16}$ to $8 \times 10^{16} \mathrm{~cm}^{-3}$ and higher. (All other parameters are kept constant.) These data clearly show that a device with a relatively high fill factor and a very linear response of the short-circuit current with light intensity is not necessarily immune to major losses of photogenerated carriers if the width of the space-charge layer is smaller than the device thickness.

\section{Impact of doping on the apparent reaction order of recombination}

Many publications show the importance of nongeminate recombination in optimized organic solar cells [43,65, 76-80]. In particular, attention is paid to the changes in apparent reaction order, which have been suggested to be indicative of changes in recombination mechanism $[43,56,76,81-83]$. In our study, the presence of $p$-type doping may significantly impact upon the charge densities involved in nongeminate recombination, especially at low light and voltage biases. Electrons will mostly originate from photon absorption while the holes originate from a combination of the ionization of $p$-type dopants and photogeneration. Here, charge extraction and transient photovoltage and photocurrent have been measured on the two thickness series. Figures 6(a) and 6(b) present experimental raw charge-extraction data at open circuit for the doped and undoped thickness series of DPP-TT-T $\mathrm{PC}_{71} \mathrm{BM}$ and show how they radically differ depending on the doping level. By collecting charges at $0 \mathrm{~V}$, the method is sensitive to excess carriers, which are swept out under short-circuit conditions and will therefore miss the carriers photogenerated in the neutral region. Furthermore, since charge extraction measures the excess charge carriers relative to short circuit in the dark, the charge extraction will not see the holes created by the ionization of the $p$-type dopants. Usually, charge-extraction data are corrected for the geometrical capacitance of the sample to distinguish the photogenerated charge carriers in the active layer from the effect of the electrodes. The correction for geometric capacitance in our case would be inappropriate if the space-charge region is thinner than the total active-layer thickness. As the correction for geometrical concentration
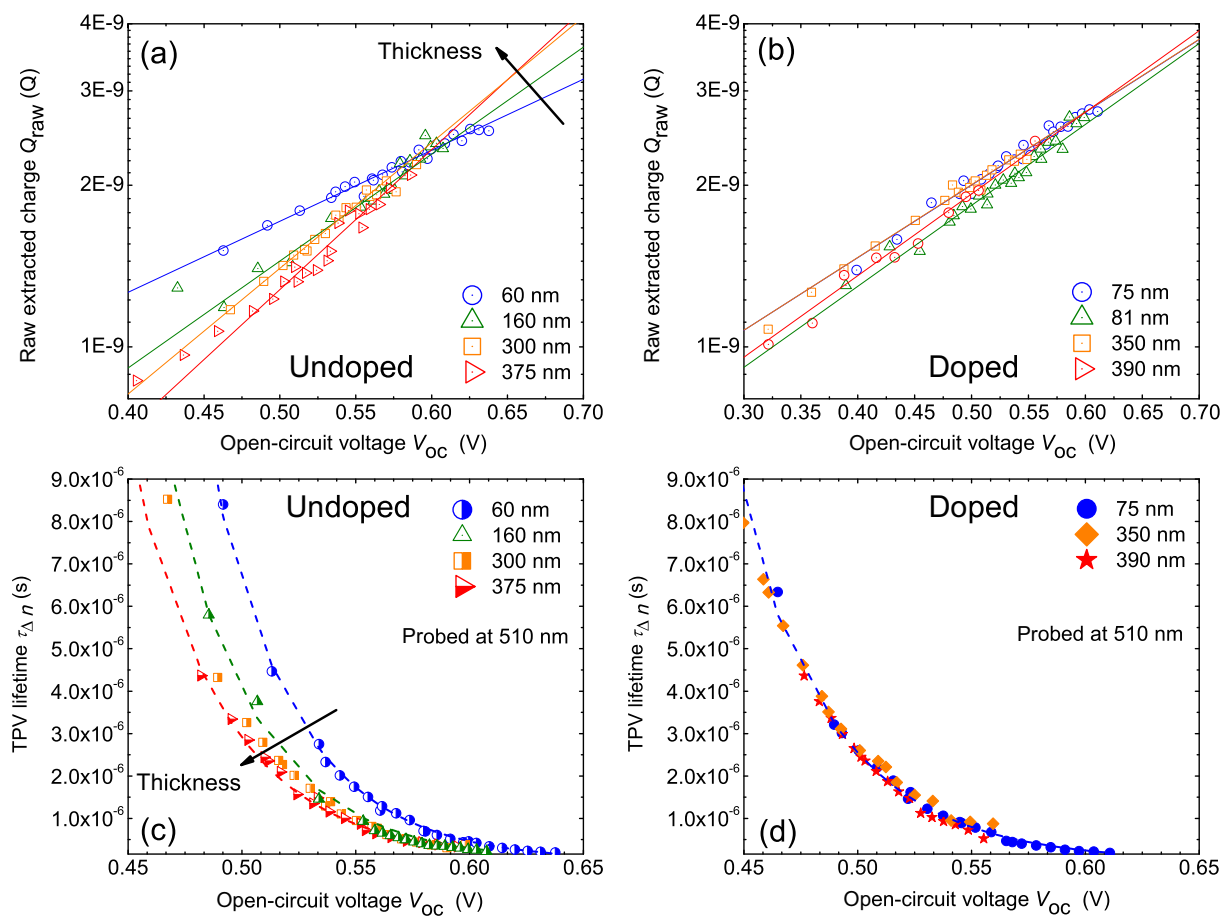

FIG. 6. Charge extraction at open circuit and TPV lifetimes for DPP-TT-T - PC 71 BM devices. Raw charges at open circuit extracted under short-circuit bias for different thicknesses for (a) low-level doping and (b) high-level doping. The way extracted excess carriers scale with light intensity is radically different depending on the doping level. TPV lifetime at different open-circuit voltages and thicknesses for (c) the low-level doping and (d) the high-level doping. 
becomes meaningless in devices with substantial doping, only raw excess carrier concentrations are shown. In the low-doping-level case where collection is made throughout the whole active layer, these experimental observations confirm the predictions of Ref. [45], where at high thickness the change in spatially averaged excess carriers with voltage is higher than in the thin devices where the spatial distribution of carriers is more heterogeneous. If the excess carrier concentration follows an exponential dependence on voltage according to

$$
\Delta n=\Delta n_{0} \exp \left(\frac{q V_{\mathrm{OC}}}{m k_{B} T}\right),
$$

it becomes apparent that in the first case in Fig. 6(a), $m$ is decreasing with thickness while the spatial distribution of excess carriers becomes more homogenous. This trend has been experimentally observed as well for polymers with low doping levels such as thieno[3,4-b]thiophene/ benzodithiophene (PTB7): $\mathrm{PC}_{71} \mathrm{BM}$ and poly[N-11"henicosanyl-2,7-carbazole-alt-5,5-(4',7'-di-2-thienyl-2',1'3'benzothiadiazole)](PCDTBT): $\mathrm{PC}_{71} \mathrm{BM}$ devices at different thicknesses as shown in the Supplemental Material, Figs. S8 and S9 [46]. On the other hand, in the doped case shown in Fig. 6(b), all the devices presented here actually have the same effective space-charge-layer width (approximately $70 \mathrm{~nm}$ ). The way the excess carriers scale with voltage is weak, similar to thin undoped devices. Hardly any change in $m$ is observed in the series of charge-extraction data at open circuit for all the doped (partially depleted) devices since the chargeextraction method is sensitive to excess carriers that only exist in the space-charge region (fixed by the high doping level). In the neutral region, the concentration of holes is mostly governed by the dopants, i.e., invariant with illumination. Furthermore, for the reason given above, collection is only efficient for carriers generated in the space-charge region, so the charge extraction would not see the excess carriers in the neutral region anyway. Therefore, the data obtained would not be expected to change with the total activelayer thickness, as observed experimentally.

In addition to the impact of doping upon extracted charge densities, doping also impacts upon the thickness dependence of observed TPV lifetimes, as shown in Figs. 6(c) and 6(d). The influence of doping was observed in different repeats of the same experiment, with, for example, more results being presented in the Supplemental Material, Fig. S10 [46], on a doped thickness series of DPP-TT-T $\mathrm{PC}_{71} \mathrm{BM}$ devices from previous batches. While the TPV lifetime versus $V_{\mathrm{OC}}$ in Fig. 6(c) changes with thickness at low doping level, no change is observed for all the doped devices presented in Fig. 6(d). (One monoexponential is necessary to fit the small perturbation lifetimes as a function of $V_{\mathrm{OC}}$.) At open circuit, recombination via traps is typically largest in the space-charge region, where electron and hole concentrations are roughly equal. This fact is confirmed by the fact that even in the doped systems the lifetime is still a monotonously decreasing function of open-circuit voltage and not just a constant as expected if recombination were dominating in the neutral zone. In this case, the space-charge region dominates the lifetime. Since the doping keeps the width of the space-charge region constant as a function of total active-layer thickness, the TPV lifetime does not change appreciably with device thickness in the doped series. In this case, if the TPV lifetime has the following form

$$
\tau_{\Delta n}=\tau_{\Delta n 0} \exp \left(-\frac{q V_{\mathrm{OC}}}{\vartheta k_{B} T}\right),
$$

$\vartheta$ has a value of $1.73 \pm 0.04$, according to Fig. 6(d). Consequently, given how insensitive the charge-extraction data and the small perturbation lifetimes are regarding the thickness of doped devices and then how strongly the dark charges are involved in bulk nongeminate recombination, the apparent reaction orders of doped devices (which usually describe how the recombination rate scales empirically with the carrier density $d n / d t=R \propto n_{\mathrm{CE}} / \tau \propto n^{\delta}$ as calculated according to Ref. [43]) are excessively high (here, $\delta \approx 5$ ) and are not a consequence of a different recombination mechanism but rather a result of the short width of the space-charge-layer depth. We have shown previously that for undoped devices, thin active-layer thicknesses can give anomalously high apparent recombination orders due to spatial inhomogeneity of the charge-carrier distributions [45,84]. This interpretation is consistent with our observation that the reaction order does not change with the total active-layer thickness since the effective layer of absorber, coinciding with the width of the space-charge region, is fixed by the doping level.

Figure 7 presents the calculated apparent reaction order of doped devices at two different thicknesses, namely, 75 and $350 \mathrm{~nm}$. For these doped devices, the width of the space-charge region is assessed to be approximately $70 \mathrm{~nm}$. While the spatial distribution of carriers changes substantially when the total active-layer thickness increases from 75 to $350 \mathrm{~nm}$, the apparent reaction order does not change at all. Obviously, the effective active layer in a $350-\mathrm{nm}$ device is actually much reduced. If the apparent recombination rate is calculated with the width of the space-charge region instead of the total active-layer thickness, the obtained $k_{\mathrm{rec}}^{*}$ coincides with that of the thin 75-nm device, in strong confirmation of the predictions of our device model. This observation highlights how similar the effects of the doping level and thin active layers are on the apparent recombination dynamics [84]. The data presented herein provide experimental evidence for the effect of unintentional doping of bulk-heterojunction solar cells on apparent carrier lifetimes, charge-extraction measurements, and reaction orders in polymer-fullerene solar cells. These experiments confirm the predictions from drift-diffusion 


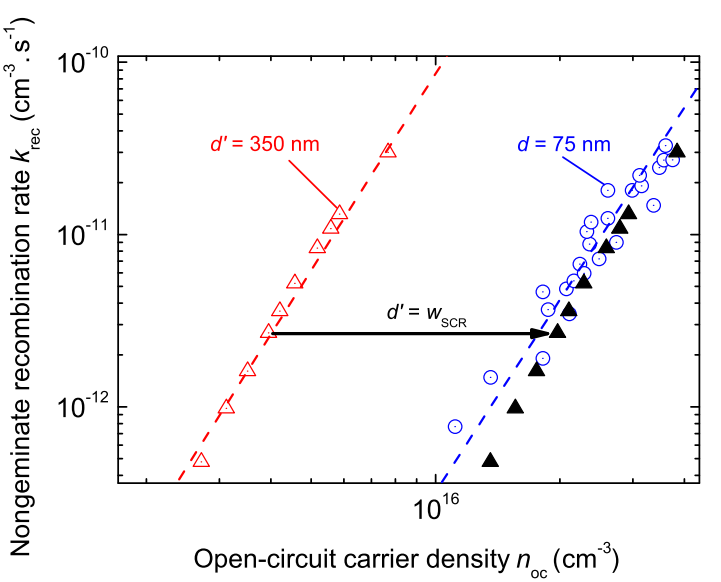

FIG. 7. Measured recombination rate $k_{\mathrm{rec}}^{*}$ function of carrier concentrations at open circuit $n_{\mathrm{OC}}$ for two DPP-TT-T $-\mathrm{PC}_{71} \mathrm{BM}$ devices with an active-layer thickness in the range of $75 \mathrm{~nm}$ (open circles) and $350 \mathrm{~nm}$ (open triangles). Both devices belong to the same series with a high doping level $N_{A}=7 \times 10^{16} \mathrm{~cm}^{-3}$. If now the recombination rate of the device $d=350 \mathrm{~nm}$ is calculated with the effective width $w_{\text {SCR }}$ of the space-charge region instead of the total active-layer thickness, the recombination rate (solid triangles) coincides with the thin undoped device.

modeling presented in Ref. [45]. In consequence, it becomes clear that the knowledge of the doping level is essential when investigating the recombination dynamics of bulk-heterojunction solar cells experimentally or via simulations.

\section{CONCLUSIONS}

To conclude, we discuss how the level of doping sites in the active layer affects the performance and apparent recombination dynamics of polymer-fullerene solar cells. In the case of high doping levels, we see that charge transport is strongly affected due to band bending at short circuit, which only allows efficient carrier collection within the space-charge layer whose thickness is constrained by the density of the dopants. Consequently, the highest optimal thickness of the active layer is limited by the intrinsic doping level and not just by the ability of the blend to transport carriers, which means that the efforts of molecular design aiming at fast charge mobilities as well as the potential of light absorption of the active material could be wasted. We emphasize in this study that although the origin of doping in organic materials might be diverse, the awareness of the doping level from molecular synthesis to final device fabrication is crucial to make the most of the potential of every material proposed to attempt to push the overall performance of organic solar cells over $10 \%$ powerconversion efficiency. This work shows that for a doping level as high as $7-8 \times 10^{16} \mathrm{~cm}^{-3}$ and beyond, the usual way of understanding device collection and recombination dynamics in organic bulk-heterojunction solar cells is challenged. Because of the fact that $n$-type doping will have similar effects to $p$-type doping in the vicinity of the other electrode, the results presented here are likely to be relevant for a wide range of organic bulk-heterojunction blends independent of their general architecture. It appears clear that the key for improving the performance of the blends will be (i) first and foremost to control or find methods to decrease the unintentional doping level so that the active layer is still fully depleted at the second interference maximum around $200-250 \mathrm{~nm}$. This requirement can be ensured by increasing the relative permittivity or decreasing the doping level to values $=6-7 \times$ $10^{15} \mathrm{~cm}^{-3}$ (see the Supplemental Material, Fig. S11 [46]). (ii) Once (i) is fulfilled, one of the main targets would be to obtain materials and nanomorphologies that enable a sufficient mobility-lifetime product up to the second interference maximum while maintaining a substantial quenching of the excitons for photogeneration.

\section{EXPERIMENTAL SECTION}

Materials and device fabrication.-More details about the purification process can be found in Ref. [27]. DPP-TT-T ${ }^{d}$ (with number-average molecular weight $M_{n}=11 \mathrm{kDa}$, weight-average molecular weight $M_{w}=69 \mathrm{kDa}$, and a polydispersity index $\mathrm{PDI}=M_{w} / M_{n}=6.2$ ) and DPP-TT-T $^{u}\left(M_{n}=24 \mathrm{kDa}, M_{w}=89 \mathrm{kDa}\right.$, and PDI $\left.=3.7\right)$ based solar cells are made with the conventional architecture ITO/PEDOT - PSS/DPP-TT-T - $\mathrm{PC}_{71} \mathrm{BM} / \mathrm{Ca} / \mathrm{Al}$. The solution uses DPP-TT-T [25] and $\mathrm{PC}_{71} \mathrm{BM}$ (Solenne) blended in a $1: 2$ blend ratio in $4: 1$ chloroform/o-dichlorobenzene leading to a final concentration of $15 \mathrm{mg} / \mathrm{mL}$. The solvents used were purchased from Sigma-Aldrich. The solutions are prepared $24 \mathrm{~h}$ prior to spin coating and kept stirring at room temperature in a sealed environment. ITO patterned on a glass substrate (Psiotech) are all precleaned with isopropanol and acetone, dried under nitrogen, and further cleaned by plasma treatment $(7 \mathrm{~min}$ at $2.5 \mathrm{mbar}$ ). Immediately following this treatment, a poly(3,4-ethylenedioxythiophene) polystyrene sulfonate (PEDOT-PSS) solution is spin coated onto the substrate with an acceleration rate of $10 \mathrm{kpm} / \mathrm{s}$ and plateau at $3500 \mathrm{rpm}$ for $40 \mathrm{~s}$. The films are annealed at $150{ }^{\circ} \mathrm{C}$ for $15 \mathrm{~min}$, resulting in a thickness of approximately $30 \mathrm{~nm}$. After cooling, the photoactive films are made by spin casting the solution on preheated substrates at $80^{\circ} \mathrm{C}$. The acceleration rate used is $10 \mathrm{krpm} / \mathrm{s}$, and the plateau speed ranges from 300 to $3500 \mathrm{rpm}$ to obtain the thickness series. For both series, the $\mathrm{Ca}$ and $\mathrm{Al}$ cathodes are deposited by evaporation whose thicknesses are assessed to be 10 and $150 \mathrm{~nm}$, respectively. The evaporation is done in one unique run so that variations in the electrode interface energetics could be neglected. Each pixel area is assessed to be $4.5 \mathrm{~mm}^{2}$.

The current density-voltage characteristics in Fig. 3 are obtained using a calibrated (AM1.5, $100 \mathrm{~mW} \mathrm{~cm}^{-2}$ ) solar simulator using a 150-W ozone-free xenon arc lamp 
(Sciencetech 200 series) with a water-cooled IR filter. The illumination is calibrated using a silicon photodiode. The measurements are obtained with a Keithley 2400 source. The voltage sweep is generally made from -1.5 to $+1 \mathrm{~V}$ with steps of $10 \mathrm{mV}$. A summary of the performance of the different devices used in this study is presented in the Supplemental Material, Table SI [46].

CE/TPC/TPV.-Charge extraction at open circuit enables measurements of $\Delta n=n_{\text {light }}-n_{\text {dark }}$, the excess carrier concentration extracted from the active layer while at open circuit under different illumination levels, i.e., different photovoltages. The sweep out is performed by switching to short circuit. The time length of each illumination is a compromise between reaching a steady state and not warming up the device being studied. Transient photovoltage is a small perturbation technique that measures the decay of the perturbation of the photovoltage resulting from the injection of a small amount of charges from a $\mathrm{N}_{2}$ dye laser while the device is held at open-circuit conditions and under constant background illumination. These two techniques lead to the calculation of the recombination rate. The details of the experimental setup and the method used have been described elsewhere $[43,69,85]$. Charge extraction at short circuit has been presented previously [70]. These measurements are conducted while the samples are in a sealed nitrogen chamber and at room temperature.

Corrected photocurrent.-To avoid overheating the devices while measuring the $J-V$ response at far reverse bias between the dark and the light conditions, pulsed measurements are used with the same LED ring as in the charge-extraction experiment described above, made of 12 white $1 \mathrm{~W}$ (Lumileds Luxeon iii/start O) with the use of a fast-switching metal oxide semiconductor field-effect transistor. The one-sun-equivalent illumination level is calibrated by matching the recorded short-circuit current $J_{\mathrm{SC}}$ and open-circuit voltage $V_{\mathrm{OC}}$ obtained under the AM1.5 solar simulator described just above. The light on time is approximately $2 \mathrm{~ms}$ to allow the steady state to be reached, and we use a much longer off time. The voltage bias is applied using a Keithley 2400 source-meter unit, and the current is measured while reading the voltage across a known resistance using a Tektronix TDS3032B with a 1-M $\Omega$ input impedance. This way, light response $J_{\text {light }}(V)$ and dark response $J_{\text {dark }}(V)$ are measured alternatively at different bias to calculate the corrected photocurrent presented in this study $\left[J_{\mathrm{ph}}(V)=J_{\text {light }}(V)-J_{\text {dark }}(V)\right]$.

Thickness measurements. - The thicknesses of the devices are measured using a Dektak profilometer precalibrated using 100-nm gold deposited on a quartz-calibration module. The deviation on the active-layer thickness, depending on the spin speed used, is no more than $15 \%$ and much lower for thin devices.

$U V$-vis spectrometer.-Ultraviolet-visible spectroscopy (UV-vis) spectra are obtained at room temperature on devices in absorbance mode using a PerkinElmer Lambda
25 spectrometer. Calibration is done using an ITO patterned on the glass substrate used in the device fabrication. The scans are conducted from 350 to $1000 \mathrm{~nm}$ with scan speeds of $460 \mathrm{~nm} / \mathrm{min}$ and a slit width of $1 \mathrm{~nm}$.

Impedance spectroscopy.-To measure the doping level in our systems, Mott-Schottky analysis on thick devices has been performed according to Ref. [53]. The measurement of the capacitance is conducted between $[-3 \mathrm{~V} ;+1 \mathrm{~V}]$ with steps of $20 \mathrm{mV}$ using a Schlumberger SI 1260 at 1, 10, and $100 \mathrm{kHz}$. During all the measurements, the devices are kept in a nitrogen-sealed chamber.

Variable-angle spectroscopic ellipsometry is performed using a rotating polarizer GES5E ellipsometer with CCD detection from SOPRALAB for blend films with three different thicknesses on quartz. The complex refractive indices are modeled by fitting the experimental data using the standard critical point model of the dielectric function.

\section{ACKNOWLEDGMENTS}

F. D. and J. R. D. are thankful of the support from the EPSRC APEX Grant No. EP/H040218/2 and SPECIFIC Grant No. EP/1019278. T. K. acknowledges funding by an Imperial College Junior Research Fellowship. We are grateful to the Ministerio de Economa y Competitividad for funding through the project PHOTOCOMB, Reference No. MAT2012-37776.

[1] E. J. Luber and J. M. Buriak, Reporting Performance in Organic Photovoltaic Devices, ACS Nano 7, 4708 (2013).

[2] R. Danieli, P. Ostoja, M. Tiecco, R. Zamboni, and C. Taliani, Poly[1,4-di-(2-thienyl)benzene]: A New Conducting Polymer, J. Chem. Soc., 1473 (1986).

[3] R. F. Heck, in Organic Reactions (Wiley, New York, 2004).

[4] N. Miyaura and A. Suzuki, Palladium-Catalyzed CrossCoupling Reactions of Organoboron Compounds, Chem. Rev. 95, 2457 (1995).

[5] K. Sonogashira, Y. Tohda, and N. Hagihara, A Convenient Synthesis of Acetylenes: Catalytic Substitutions of Acetylenic Hydrogen with Bromoalkenes, Iodoarenes and Bromopyridines, Tetrahedron Lett. 16, 4467 (1975).

[6] J. K. Stille, The Palladium-Catalyzed Cross-Coupling Reactions of Organotin Reagents with Organic Electrophiles [New Synthetic Methods (58)], Angew. Chem., Int. Ed. Engl. 25, 508 (1986).

[7] B. Tieke, A. R. Rabindranath, K. Zhang, and Y. Zhu, Conjugated Polymers Containing Diketopyrrolopyrrole Units in the Main Chain, Beilstein J. Org. Chem. 6, 830 (2010).

[8] T. Yamamoto, A. Morita, Y. Miyazaki, T. Maruyama, H. Wakayama, Z. H. Zhou, Y. Nakamura, T. Kanbara, S. Sasaki, and K. Kubota, Preparation of $\pi$-Conjugated Poly (thiophene-2, 5-diyl), Poly(p-phenylene), and Related Polymers Using Zerovalent Nickel Complexes. Linear Structure 
and Properties of the $\pi$-Conjugated Polymers, Macromolecules 25, 1214 (1992).

[9] Peter T. Landsberg, Recombination in Semiconductors (Cambridge University Press, Cambridge, England, 1991).

[10] R. A. Street, Hydrogenated Amorphous Silicon (Cambridge University Press, Cambridge, 1991).

[11] H. Frohne, S. E. Shaheen, C. J. Brabec, D. C. Müller, N. Serdar Sariciftci, and K. Meerholz, Influence of the Anodic Work Function on the Performance of Organic Solar Cells, ChemPhysChem 3, 795 (2002).

[12] B. Lüssem, M. Riede, and K. Leo, Doping of Organic Semiconductors, Phys. Status Solidi (a) 210, 9 (2013).

[13] S. Nicht, H. Kleemann, A. Fischer, K. Leo, and B. Lüssem, Functionalized p-Dopants as Self-Assembled Monolayers for Enhanced Charge Carrier Injection in Organic Electronic Devices, Org. Electron. 15, 654 (2014).

[14] E. Siebert-Henze, V. G. Lyssenko, J. Fischer, M. Tietze, R. Brueckner, T. Menke, K. Leo, and M. Riede, Electroabsorption Studies of Organic p-i-n Solar Cells: Increase of the Built-In Voltage by Higher Doping Concentration in the Hole Transport Layer, Org. Electron. 15, 563 (2014).

[15] G. Dicker, M. P. de Haas, J. M. Warman, D. M. de Leeuw, and L.D.A. Siebbeles, The Disperse Charge-Carrier Kinetics in Regioregular Poly(3-hexylthiophene), J. Phys. Chem. B 108, 17818 (2004).

[16] A. J. Ferguson, N. Kopidakis, S. E. Shaheen, and G. Rumbles, Dark Carriers, Trapping, and Activation Control of Carrier Recombination in Neat P3HT and P3HT:PCBM Blends, J. Phys. Chem. C 115, 23134 (2011).

[17] B. A. Gregg, Transport in Charged Defect-Rich $\pi$-Conjugated Polymers, J. Phys. Chem. C 113, 5899 (2009).

[18] Z. Liang, A. Nardes, D. Wang, J. J. Berry, and B. A. Gregg, Defect Engineering in $\pi$-Conjugated Polymers, Chem. Mater. 21, 4914 (2009).

[19] H.-H. Liao, C.-M. Yang, C.-C. Liu, S.-F. Horng, H.-F. Meng, and J.-T. Shy, Dynamics and Reversibility of Oxygen Doping and De-doping for Conjugated Polymer, J. Appl. Phys. 103, 104506 (2008).

[20] A. J. Morfa, A. M. Nardes, S. E. Shaheen, N. Kopidakis, and J. van de Lagemaat, Time-of-Flight Studies of Electron-Collection Kinetics in Polymer:Fullerene BulkHeterojunction Solar Cells, Adv. Funct. Mater. 21, 2580 (2011).

[21] A. J. Mozer, N. S. Sariciftci, A. Pivrikas, R. Österbacka, G. Juŝka, L. Brassat, and H. Bässler, Charge Carrier Mobility in Regioregular Poly(3-hexylthiophene) Probed by Transient Conductivity Techniques: A Comparative Study, Phys. Rev. B 71, 035214 (2005).

[22] J. Schafferhans, A. Baumann, A. Wagenpfahl, C. Deibel, and V. Dyakonov, Oxygen Doping of P3HT:PCBM Blends: Influence on Trap States, Charge Carrier Mobility and Solar Cell Performance, Org. Electron. 11, 1693 (2010).

[23] V. A. Trukhanov, V. V. Bruevich, and D. Y. Paraschuk, Effect of Doping on Performance of Organic Solar Cells, Phys. Rev. B 84, 205318 (2011).

[24] T. Kirchartz, T. Agostinelli, M. Campoy-Quiles, W. Gong, and J. Nelson, Understanding the Thickness-Dependent Performance of Organic Bulk Heterojunction Solar Cells:
The Influence of Mobility, Lifetime, and Space Charge, J. Phys. Chem. Lett. 3, 3470 (2012).

[25] H. Bronstein, Z. Chen, R. S. Asharf, W. Zhang, J. Du, J. R. Durrant, P. S. Tuladhar, K. Song, S. E. Watkins, Y. Geerts, M. M. Wienk, R. A. J. Janssen, T. Anthopoulos, H. Sirringhaud, M. Heeney, and I. McCulloch, Thieno[3, 2 - b]thiophene-Diketopyrrolopyrrole-Containing Polymers for High-Performance Organic Field-Effect Transistors and Organic Photovoltaic Devices, J. Am. Chem. Soc. 133, 3272 (2011).

[26] I. Meager, R. S. Ashraf, S. Mollinger, B. C. Schroeder, H. Bronstein, D. Beatrup, M. S. Vezie, T. Kirchartz, A. Salleo, J. Nelson, and I. McCulloch, Photocurrent Enhancement from Diketopyrrolopyrrole Polymer Solar Cells through Alkyl-Chain Branching Point Manipulation, J. Am. Chem. Soc. 135, 11537 (2013).

[27] R. S. Ashraf, B. C. Schroeder, H. A. Bronstein, Z. Huang, S. Thomas, R. Joseph Kline, C. J. Brabec, P. Rannou, T. D. Anthopoulos, J. R. Durrant, and I. McCulloch, The Influence of Polymer Purification on Photovoltaic Device Performance of a Series of Indacenodithiophene Donor Polymers, Adv. Mater. 25, 2029 (2013).

[28] M. Jørgensen, K. Norrman, and F. C. Krebs, Stability/ Degradation of Polymer Solar Cells, Sol. Energy Mater. Sol. Cells 92, 686 (2008).

[29] J. Kettle, M. Horie, L. A. Majewski, B. R. Saunders, S. Tuladhard, J. Nelson, and M. L. Turner, Optimisation of PCPDTBT Solar Cells Using Polymer Synthesis with Suzuki Coupling, Sol. Energy Mater. Sol. Cells 95, 2186 (2011).

[30] J. Kuwabara, T. Yasuda, S. J. Choi, W. Lu, K. Yamazaki, S. Kagaya, L. Han, and T. Kanbara, Direct Arylation Polycondensation: A Promising Method for the Synthesis of Highly Pure, High-Molecular-Weight Conjugated Polymers Needed for Improving the Performance of Organic Photovoltaics, Adv. Funct. Mater. 24, 3226 (2014).

[31] W. R. Mateker, J. D. Douglas, C. Cabanetos, I. T. SachsQuintana, J. A. Bartelt, E. T. Hoke, A. El Labban, P. M. Beaujuge, J. M. J. Frechet, and M. D. McGehee, Improving the Long-Term Stability of PBDTTPD Polymer Solar Cells through Material Purification Aimed at Removing Organic Impurities, Energy Environ. Sci. 6, 2529 (2013).

[32] M. P. Nikiforov, B. Lai, W. Chen, S. Chen, R. D. Schaller, J. Strzalka, J. Maser, and S. B. Darling, Detection and Role of Trace Impurities in High-Performance Organic Solar Cells, Energy Environ. Sci. 6, 1513 (2013).

[33] J. A. Barker, C. M. Ramsdale, and N. C. Greenham, Modeling the Current-Voltage Characteristics of Bilayer Polymer Photovoltaic Devices, Phys. Rev. B 67, 075205 (2003).

[34] J. Cuiffi, T. Benanti, W. J. Nam, and S. Fonash, Modeling of Bulk and Bilayer Organic Heterojunction Solar Cells, Appl. Phys. Lett. 96, 143307 (2010).

[35] R. Hausermann, E. Knapp, M. Moos, N. A. Reinke, T. Flatz, and B. Ruhstaller, Coupled Optoelectronic Simulation of Organic Bulk-Heterojunction Solar Cells: Parameter Extraction and Sensitivity Analysis, J. Appl. Phys. 106, 104507 (2009).

[36] L. J. A. Koster, E. C. P. Smits, V. D. Mihailetchi, and P. W. M. Blom, Device Model for the Operation of Polymer/Fullerene Bulk Heterojunction Solar Cells, Phys. Rev. B 72, 085205 (2005). 
[37] T. Kirchartz, J. Mattheis, and U. Rau, Detailed Balance Theory of Excitonic and Bulk Heterojunction Solar Cells, Phys. Rev. B 78, 235320 (2008).

[38] J. D. Kotlarski, P. W. M. Blom, L. J. A. Koster, M. Lenes, and L. H. Slooff, Combined Optical and Electrical Modeling of Polymer:Fullerene Bulk Heterojunction Solar Cells, J. Appl. Phys. 103, 084502 (2008).

[39] S. Lacic and O. Inganas, Modeling Electrical Transport in Blend Heterojunction Organic Solar Cells, J. Appl. Phys. 97, 124901 (2005).

[40] R. A. Marsh, C. Groves, and N. C. Greenham, A Microscopic Model for the Behavior of Nanostructured Organic Photovoltaic Devices, J. Appl. Phys. 101, 083509 (2007).

[41] C. M. Martin, V. M. Burlakov, H. E. Assender, and D. A. R. Barkhouse, A Numerical Model for Explaining the Role of the Interface Morphology in Composite Solar Cells, J. Appl. Phys. 102, 104506 (2007).

[42] S. S. Mottaghian, M. Biesecker, K. Bayat, and M. F. Baroughi, Unified Electronic Charge Transport Model for Organic Solar Cells, J. Appl. Phys. 114, 024501 (2013).

[43] C. G. Shuttle, B. O’Regan, A. M. Ballantyne, J. Nelson, D. D. C. Bradley, and J. R. Durrant, Bimolecular Recombination Losses in Polythiophene: Fullerene Solar Cells, Phys. Rev. B 78, 113201 (2008).

[44] T. Kirchartz, B. E. Pieters, J. Kirkpatrick, U. Rau, and J. Nelson, Recombination via Tail States in Polythiophene: Fullerene Solar Cells, Phys. Rev. B 83, 115209 (2011).

[45] T. Kirchartz and J. Nelson, Meaning of Reaction Orders in Polymer:Fullerene Solar Cells, Phys. Rev. B 86, 165201 (2012).

[46] See Supplemental Material at http://link.aps.org/ supplemental/10.1103/PhysRevX.5.011032 for summary of the performance of the different devices.

[47] T. Kirchartz and J. Nelson, Device Modelling of Organic Bulk Heterojunction Solar Cells, Top. Curr. Chem. 352, 279 (2014).

[48] G. F. A. Dibb, M.-A. Muth, T. Kirchartz, S. Engmann, H. Hoppe, G. Gobsch, M. Thelakkat, N. Blouin, S. Tierney, M. Carrasco-Orozco, J. R. Durrant, and J. Nelson, Influence of Doping on Charge Carrier Collection in Normal and Inverted Geometry Polymer:Fullerene Solar Cells, Sci. Rep. 3, 3335 (2013).

[49] J. Bisquert and G. Garcia-Belmonte, On Voltage, Photovoltage, and Photocurrent in Bulk Heterojunction Organic Solar Cells, J. Phys. Chem. Lett. 2, 1950 (2011).

[50] P. P. Boix, G. Garcia-Belmonte, U. Muñecas, M. Neophytou, C. Waldauf, and R. Pacios, Determination of Gap Defect States in Organic Bulk Heterojunction Solar Cells from Capacitance Measurements, Appl. Phys. Lett. 95, 233302 (2009).

[51] G. Garcia-Belmonte, A. Guerrero, and J. Bisquert, Elucidating Operating Modes of Bulk-Heterojunction Solar Cells from Impedance Spectroscopy Analysis, J. Phys. Chem. Lett. 4, 877 (2013).

[52] J. Heath and P. Zabierowski, in Advanced Characterization Techniques for Thin Film Solar Cells (Wiley-VCH Verlag, Weinheim, Germany, 2011), p. 81-105.

[53] T. Kirchartz, W. Gong, S. A. Hawks, T. Agostinelli, R. C. I. MacKenzie, Y. Yang, and J. Nelson, Sensitivity of the
Mott-Schottky Analysis in Organic Solar Cells, J. Phys. Chem. C 116, 7672 (2012).

[54] G. Perrier, R. de Bettignies, S. Berson, N. Lemaître, and S. Guillerez, Impedance Spectrometry of Optimized Standard and Inverted P3HT-PCBM Organic Solar Cells, Sol. Energy Mater. Sol. Cells 101, 210 (2012).

[55] S. C. Jain, W. Geens, A. Mehra, V. Kumar, T. Aernouts, J. Poortmans, R. Mertens, and M. Willander, Injection- and Space Charge Limited-Currents in Doped Conducting Organic Materials, J. Appl. Phys. 89, 3804 (2001).

[56] A. J. Mozer, G. Dennler, N. S. Sariciftci, M. Westerling, A. Pivrikas, R. Österbacka, and G. Juška, Time-Dependent Mobility and Recombination of the Photoinduced Charge Carriers in Conjugated Polymer/Fullerene Bulk Heterojunction Solar Cells, Phys. Rev. B 72, 035217 (2005).

[57] T. Ameri, G. Dennler, C. Waldauf, P. Denk, K. Forberich, M. C. Scharber, C. J. Brabec, and K. Hingerl, Realization, Characterization, and Optical Modeling of Inverted BulkHeterojunction Organic Solar Cells, J. Appl. Phys. 103, 084506 (2008).

[58] Y. M. Nam, J. Huh, and W. H. Jo, Optimization of Thickness and Morphology of Active Layer for High Performance of Bulk-Heterojunction Organic Solar Cells, Sol. Energy Mater. Sol. Cells 94, 1118 (2010).

[59] L. Zeng, C. W. Tang, and S. H. Chen, Effects of Active Layer Thickness and Thermal Annealing on Polythiophene: Fullerene Bulk Heterojunction Photovoltaic Devices, Appl. Phys. Lett. 97, 053305 (2010).

[60] V. Dyakonov, Electrical Aspects of Operation of PolymerFullerene Solar Cells, Thin Solid Films 451-452, 493 (2004).

[61] D. Gupta, S. Mukhopadhyay, and K. S. Narayan, Fill Factor in Organic Solar Cells, Sol. Energy Mater. Sol. Cells 94, 1309 (2010).

[62] L. J. Koster, M. Kemerink, M. M. Wienk, K. Maturova, and R. A. Janssen, Quantifying Bimolecular Recombination Losses in Organic Bulk Heterojunction Solar Cells, Adv. Mater. 23, 1670 (2011).

[63] Jan D. Kotlarski, D. J. D. Moet, and P. W. M. Blom, Role of Balanced Charge Carrier Transport in Low Band Gap Polymer:Fullerene Bulk Heterojunction Solar Cells, J. Polym. Sci. B 49, 708 (2011).

[64] M. Lenes, L. J. A. Koster, V. D. Mihailetchi, and P. W. M. Blom, Thickness Dependence of the Efficiency of Polymer: Fullerene Bulk Heterojunction Solar Cells, Appl. Phys. Lett. 88, 243502 (2006).

[65] W. Li, K. H. Hendriks, W. S. Christian Roelofs, Y. Kim, M. M. Wienk, and R. A. J. Janssen, Efficient Small Bandgap Polymer Solar Cells with High Fill Factors for $300 \mathrm{~nm}$ Thick Films, Adv. Mater. 25, 3182 (2013).

[66] A. Pivrikas, G. Juška, A. J. Mozer, M. Scharber, K. Arlauskas, N. S. Sariciftci, H. Stubb, and R. Österbacka, Bimolecular Recombination Coefficient as a Sensitive Testing Parameter for Low-Mobility Solar-Cell Materials, Phys. Rev. Lett. 94, 176806 (2005).

[67] K. Vandewal, S. Himmelberger, and A. Salleo, Structural Factors That Affect the Performance of Organic Bulk Heterojunction Solar Cells, Macromolecules 46, 6379 (2013). 
[68] C. G. Shuttle, B. O’Regan, A. M. Ballantyne, J. Nelson, D. D. C. Bradley, J. de Mello, and J.R. Durrant, Experimental Determination of the Rate Law for Charge Carrier Decay in a Polythiophene: Fullerene Solar Cell, Appl. Phys. Lett. 92, 093311 (2008).

[69] C. G. Shuttle, A. Maurano, R. Hamilton, B. O'Regan, J. C. de Mello, and J. R. Durrant, Charge Extraction Analysis of Charge Carrier Densities in a Polythiophene/Fullerene Solar Cell: Analysis of the Origin of the Device Dark Current, Appl. Phys. Lett. 93, 183501 (2008).

[70] C. G. Shuttle, R. Hamilton, J. Nelson, B. C. O'Regan, and J. R. Durrant, Measurement of Charge-Density Dependence of Carrier Mobility in an Organic Semiconductor Blend, Adv. Funct. Mater. 20, 698 (2010).

[71] J. Gao, F. Hide, and H. L. Wang, Efficient Photodetectors and Photovoltaic Cells from Composites of Fullerenes and Conjugated Polymers: Photoinduced Electron Transfer, Synth. Met. 84, 979 (1997).

[72] D. Gebeyehu, M. Pfeiffer, B. Maennig, J. Drechsel, A. Werner, and K. Leo, Highly Efficient $p$-i-n Type Organic Photovoltaic Devices, Thin Solid Films 451-452, 29 (2004).

[73] I. Riedel, J. Parisi, V. Dyakonov, L. Lutsen, D. Vanderzande, and J. C. Hummelen, Effect of Temperature and Illumination on the Electrical Characteristics of Polymer-Fullerene Bulk-Heterojunction Solar Cells, Adv. Funct. Mater. 14, 38 (2004).

[74] P. Schilinsky, C. Waldauf, and C. J. Brabec, Recombination and Loss Analysis in Polythiophene Based Bulk Heterojunction Photodetectors, Appl. Phys. Lett. 81, 3885 (2002).

[75] J. K. J. van Duren, X. Yang, J. Loos, C. W. T. BulleLieuwma, A. B. Sieval, J. C. Hummelen, and R. A. J. Janssen, Relating the Morphology of Poly(p-phenylene vinylene)/Methanofullerene Blends to Solar-Cell Performance, Adv. Funct. Mater. 14, 425 (2004).

[76] S. Chen, K. R. Choudhury, J. Subbiah, C. M. Amb, J. R. Reynolds, and F. So, Photo-carrier Recombination in Polymer Solar Cells Based on P3HT and Silole-Based Copolymer, Adv. Energy Mater. 1, 963 (2011).

[77] D. Credgington, F. C. Jamieson, B. Walker, T. Q. Nguyen, and J. R. Durrant, Quantification of Geminate and Non- geminate Recombination Losses within a SolutionProcessed Small-Molecule Bulk Heterojunction Solar Cell, Adv. Mater. 24, 2135 (2012).

[78] C. Deibel, A. Baumann, and V. Dyakonov, Polaron Recombination in Pristine and Annealed Bulk Heterojunction Solar Cells, Appl. Phys. Lett. 93, 163303 (2008).

[79] G. Garcia-Belmonte, A. Munar, E. M. Barea, J. Bisquert, I. Ugarte, and R. Pacios, Charge Carrier Mobility and Lifetime of Organic Bulk Heterojunctions Analyzed by Impedance Spectroscopy, Org. Electron. 9, 847 (2008).

[80] C. M. Proctor, C. Kim, D. Neher, and T.-Q. Nguyen, Nongeminate Recombination and Charge Transport Limitations in Diketopyrrolopyrrole-Based Solution-Processed Small Molecule Solar Cells, Adv. Funct. Mater. 23, 3584 (2013).

[81] A. Foertig, A. Baumann, D. Rauh, V. Dyakonov, and C. Deibel, Charge Carrier Concentration and Temperature Dependent Recombination in Polymer-Fullerene Solar Cells, Appl. Phys. Lett. 95, 052104 (2009).

[82] G. Garcia-Belmonte, P. P. Boix, J. Bisquert, M. Sessolo, and H. J. Bolink, Simultaneous Determination of Carrier Lifetime and Electron Density-of-States in P3HT:PCBM Organic Solar Cells under Illumination by Impedance Spectroscopy, Sol. Energy Mater. Sol. Cells 94, 366 (2010).

[83] W. L. Leong, S. R. Cowan, and A. J. Heeger, Differential Resistance Analysis of Charge Carrier Losses in Organic Bulk Heterojunction Solar Cells: Observing the Transition from Bimolecular to Trap-Assisted Recombination and Quantifying the Order of Recombination, Adv. Energy Mater. 1, 517 (2011).

[84] F. Deledalle, P. S. Tuladhar, J. Nelson, J. R. Durrant, and T. Kirchartz, Understanding the Apparent Charge Density Dependence of Mobility and Lifetime in Organic Bulk Heterojunction Solar Cells, J. Phys. Chem. C 118, 8837 (2014).

[85] A. Maurano, R. Hamilton, C. G. Shuttle, A. M. Ballantyne, J. Nelson, B. O'Regan, W. Zhang, I. McCulloch, H. Azimi, M. Morana, C. J. Brabec, and J. R. Durrant, Recombination Dynamics as a Key Determinant of Open Circuit Voltage in Organic Bulk Heterojunction Solar Cells: A Comparison of Four Different Donor Polymers, Adv. Mater. 22, 4987 (2010). 